UDC 327.83(470+571)

Submitted: 01.08.2018

LBC 66.4(2Poc), 0

Accepted: 05.10.2018

\title{
PUBLIC DIPLOMACY AS A TOOL OF THE RUSSIAN SOFT POWER IMPLEMENTATION
}

\author{
Elena F. Parubochaya \\ Volgograd State University, Volgograd, Russian Federation \\ Nikita V. Piskunov \\ Volgograd State University, Volgograd, Russian Federation
}

\begin{abstract}
Introduction. In this paper the public diplomacy of the Russian Federation is considered as one of the important tools of implementing modern Russian ideas and principles of soft power. We observe increased importance of implementing different activity directions within the public diplomacy in the conditions of the difficult international situation. Many of them are at the stage of formation. At the same time, a complex work in this direction can allow to strengthen public diplomacy positions as the effective tool implementation of Russian soft power. Methods. Comparative method allows matching the main specifics of public diplomacy activity and soft power implementation that let us concluding that public diplomacy is the soft power tool. Using this method was possible to establish that realization resources of public diplomacy and soft power are substantially identical. Analysis. The analysis of Russian public diplomacy activity and its clear relation with the main principles of the soft power which are implemented by the modern Russian government is based on search principle of such phenomena extinguishing features as the public diplomacy and soft power. It should be mentioned that many public diplomacy functions are coinciding with main tasks of soft power. The possibility for further public diplomacy institutionalization has been emphasized, and the specifics of unified direction of soft power and Russian diplomacy actions have been characterized. Results. In the result of the research it was revealed that public diplomacy is a direct tool of the soft power implementation. An attempt has been made to delimit the definitions of 'society diplomacy', 'public diplomacy' and 'soft power'. Russian researchers' approaches to public diplomacy understanding and its activity directions have been determined, the most realized directions have also been revealed.

E. F. Parubochaya has revealed key differences in the definitions of 'society diplomacy' and 'public diplomacy', and determined main interlinks of Russian public diplomacy and soft power. N. V. Piskunov has marked basic displays of the modern Russian soft power.
\end{abstract}

Key words: society diplomacy, public diplomacy, soft power, cultural diplomacy, Russian foreign policy.

Citation. Parubochaya E.F., Piskunov N.V. Public Diplomacy as a Tool of the Russian Soft Power Implementation. Vestnik Volgogradskogo gosudarstvennogo universiteta. Seriya 4, Istoriya. Regionovedenie. Mezhdunarodnye otnosheniya [Science Journal of Volgograd State University. History. Area Studies. International Relations], 2018, vol. 23, no. 6, pp. 197-207. (in Russian). DOI: https://doi.org/10.15688/jvolsu4.2018.6.16

\section{ОБЩЕСТВЕННАЯ ДИПЛОМАТИЯ КАК ИНСТРУМЕНТ РЕАЛИЗАЦИИ РОССИЙСКОЙ «МЯГКОЙ СИЛЫ»}

\section{Елена Федоровна Парубочая}

Волгоградский государственный университет, г. Волгоград, Российская Федерация

\section{Никита Владимирович Пискунов}

Волгоградский государственный университет, г. Волгоград, Российская Федерация 


\section{ПОЛИТИЧЕСКИЕ НАУКИ И РЕГИОНОВЕДЕНИЕ}

Аннотация. Введение. В данной статье общественная дипломатия Российской Федерации рассматривается в качестве одного из основных инструментов реализации идей и принципов современной российской «мягкой силы». В условиях сложной международной обстановки усиливается значимость реализации различных направлений деятельности общественной дипломатии. Многие из них находятся на этапе формирования, вместе с тем комплексная работа в данной области позволит укрепить позиции общественной дипломатии в качестве эффективного инструмента реализации российской «мягкой силы». Была предпринята попытка разграничить понятия «общественная дипломатия», «публичная дипломатия» и «мягкая сила». Выделены подходы российских исследователей к пониманию общественной дипломатии и направлений деятельности, выявлены наиболее реализуемые направления. Memodbl. Использование сравнительного метода позволило сопоставить основные особенности деятельности общественной дипломатии и реализации «мягкой силы» и установить, что средства реализации общественной дипломатии и «мягкой силы» являются в основной массе идентичными. Анализ. В результате анализа деятельности российской общественной дипломатии и ее соответствия основным принципам «мягкой силы», реализуемой современным российским правительством, выявлены отличные черты данных феноменов. Особо обращается внимание на то, что многие функции общественной дипломатии совпадают с основными задачами «мягкой силы», подчеркнута возможность дальнейшей институционализации общественной дипломатии, охарактеризованы особенности единой направленности в действиях «мягкой силы» и российской дипломатии. Результаты. В результате проведенного исследования было выявлено, что общественная дипломатия является прямым инструментом проявления «мягкой силы».

В данной статье Е.Ф. Парубочей были выявлены ключевые различия в понятиях «общественная дипломатия» и «публичная дипломатия» и определена взаимосвязь российской общественной дипломатии и «мягкой силы». Н.В. Пискуновым были определены основные проявления современной российской «мягкой силы».

Ключевые слова: общественная дипломатия, публичная дипломатия, «мягкая сила», культурная дипломатия, российская внешняя политика.

Цитирование. Парубочая Е. Ф., Пискунов Н. В. Общественная дипломатия как инструмент реализации российской «мягкой силы» // Вестник Волгоградского государственного университета. Серия 4, История. Регионоведение. Международные отношения. - 2018. - Т. 23, № 6. - С. 197-207. - DOI: https://doi.org/10.15688/ jvolsu4.2018.6.16

Введение. В начале 2000-х гг. в российской общественности стали активно говорить об общественной дипломатии, ее важности и значимости в процессе реализации российской внешней политики. Одновременно с данным термином встречается и другой термин - «публичная дипломатия», что порождает в научной среде множество дискуссий относительно их разграничения. В политическом дискурсе встречается также термин «народная дипломатия», который вносит еще большую неразбериху в понятийный аппарат политологов и международников. Если попытаться дать определение «народной дипломатии», то в широком понимании можно говорить о непрерывном процессе общения народов, отдельных граждан разных государств с целью взаимного познания, взаимообогащения. В результате разобраться с дефинициями публичной и общественной дипломатии становится еще сложнее. Зачастую их рассматривают как синонимы. Путаница связана с тем, что и общественная и публичная дипломатия переводятся на английс- кий язык как «public diplomacy». В зарубежных источниках также упоминается о том, что нет единого определения. Мир слишком быстро меняется, и мы живем в век новой общественной дипломатии, когда частные компании, неправительственные организации, отдельные группы добровольцев и даже отдельные лица могут влиять на то, как складываются международные коммуникации. И если ранее пропаганда была ядром публичной дипломатии, то сегодня это уже не так. Технологическая революция и трансформация формата межличностного общения, интеграция населения разных стран в единую информационную сеть Интернет требуют новых подходов к пониманию процессов общественной дипломатии [15]. Не углубляясь в выявление терминологических отличий публичной и общественной дипломатии, которые, безусловно, присутствуют при переводе на русский язык понятия «public diplomacy», акцентируем внимание на рассмотрении общественной дипломатии как инструмента реализации Россией своей «мягкой силы». 
В последнее время использование общественной дипломатии стало одним из наиболее эффективных государственных ресурсов в достижении внешнеполитических целей и позиционировании государства на международной арене, а также в системе международных отношений в целом. Российская Федерация также реализует этот немаловажный инструмент в своей внешнеполитической деятельности. Так называемая «мягкая сила», или «soft power», зачастую выполняет функции, очень схожие с деятельностью общественной дипломатии. Соответственно, целью данного научного исследования является определение общественной дипломатии Российской Федерации в качестве основного инструмента реализации идей и принципов современной российской «мягкой силы».

Методы исследования. Под общественной дипломатией в современном мире принято понимать совместные действия государства и гражданского общества на международной арене в ходе двустороннего или многостороннего взаимодействия с различными зарубежными государствами. При этом подключение общественности, множества неправительственных организаций, экспертного и академического сообщества, деловых кругов и деятелей культуры к государственным усилиям способствует укреплению взаимопонимания между странами и народами, развитию гуманитарного сотрудничества, продвижению интересов государства за рубежом, выработке основных решений по многочисленным проблемам международной повестки дня. Рассматривая общественную дипломатию, можно встретить различные термины: на современном этапе исследователями еще не выработано четкое определение данного феномена.

Необходимо определить, что понимается под «мягкой силой» и как она соотносится с термином «общественная дипломатия». По мнению американского исследователя Дж. Ная, «мягкая сила»- это способность добиваться желаемого на основе добровольного участия союзников, а не с помощью принуждения [14]. Необходимо отметить, что концепция Дж. Ная появилась в 1980-х гг. в Соединенных Штатах Америки и продемонстрировала совершенно новые возможности теории неолиберализма в международных отно- шениях, а также отличие концепции «мягкой силы» от остальных существовавших теоретико-методологических установок.

Согласно концепции «мягкой силы», любое государство репрезентует себя исключительно с положительной стороны, чтобы достичь необходимых целей на международной арене. Общественная дипломатия с ее стремлением установить равноправный диалог с иными государствами и народами посредством распространения государственной культуры и ценностей способствует продвижению целей реализации политики «мягкой силы». В этой связи можно с уверенностью сказать, что объектом научного исследования выступает «мягкая сила» современной Российской Федерации, а предметом исследования - общественная дипломатия как инструмент реализации российской «мягкой силы».

Использование сравнительного метода позволило сравнить особенности общественной дипломатии и «мягкой силы». В результате был сделан вывод о том, что общественная дипломатия обладает множеством функций, которые пересекаются по своему содержанию с функциями «мягкой силой». Иными словами, общественная дипломатия является своеобразным инструментом исполнения основных задач «мягкой силы» государства.

Рассматривая российскую «мягкую силу», можно выявить основную направленность и особенности общественной дипломатии России. Кроме того, в данном анализе устанавливаются объективные и субъективные факторы проявления «мягкой силы» и выявляются главные взаимосвязи рассматриваемых социально-политических и международных феноменов.

Подобная постановка научно-исследовательского вопроса взаимосвязи «мягкой силы» и общественной дипломатии позволяет решить основные вопросы практической деятельности российской «мягкой силы», а также определить дальнейшие векторы развития общественной дипломатии и ее дальнейшей институционализации.

Дискуссия. На рубеже XX-XXI вв. в российском политическом дискурсе стали появляться термины «мягкая сила», «публичная дипломатия» и «общественная дипломатия». В новом столетии руководство РФ всерьез за- 
думалось о необходимости использования «мягкой силы» в целях возврата страны к лидирующим позициям на международной арене. Традиционно в России концепция «мягкой силы» воспринимается как осуществление несилового давления на иных акторов международных отношений, однако зачастую «мягкая сила» отождествляется и с пропагандой. В этой связи необходимо определить, что является в теоретическом понимании пропагандой, а что «мягкой силой».

Отечественный исследователь в области теории международных отношений (далее ТМО) М.М. Лебедева предложила свою классификацию отличительных черт пропаганды и «мягкой силы». По ее мнению, «мягкая сила» обладает следующими характеристиками: 1) не допускает навязывания (противоположная сторона сама должна сделать выбор) или стимулирования; 2) в рамках неолиберальной концепции ТМО допускает внимание к интересам другого; 3 ) ориентирована на долгосрочное взаимодействие с партнером; 4) избегает манипулятивных стратегий; 5) ориентирована на диалог и воспринимает противоположную сторону в качестве субъекта; 6) предполагает создание доверительных отношений между акторами международных отношений [5, с. 215]. М.М. Лебедева полагает, что категория «пропаганда» обладает следующими, совершенно отличными от «мягкой силы» чертами: 1) допускает навязывание (принуждение), а также различные виды стимулирования, в том числе и вознаграждения; 2) используется исключительно в рамках реалистской концепции ТМО, то есть ориентирована на соблюдение собственных геополитических интересов; 3) не имеет способности к работе в долгосрочной перспективе; 4) ориентирована на монолог и использует противоположную сторону исключительно в качестве объекта своей деятельности; 5) формирование доверительных отношений не является фокусом приоритетного внимания [5, с. 215]. Отсюда можно сделать вывод о том, что «мягкая сила» и пропаганда являются абсолютно разнородными понятиями, которые практически никаким образом не связаны между собой, подтверждением служит тот факт, что рассматриваемые феномены используют различный идеологический аппа- рат в своей деятельности, при этом «мягкая сила» стремится к соблюдению интересов страны, которая проводит данную политику.

В этой связи крайне важным представляется определение основных задач деятельности современной российской «мягкой силы». По мнению эксперта Российского совета по международным делам (далее - РСМД) А. Долинского, «мягкая сила» как фактор усиления политического влияния России в мире предполагает выполнение трех основных задач: 1) информирование зарубежной общественности о позиции российского государства и общества по тем или иным вопросам международной повестки дня; 2) получение обратной связи от зарубежной общественности; 3) участие в выработке внешнеполитической позиции России с учетом мнения зарубежной общественности [3].

Необходимо подчеркнуть, что на сегодняшний день происходит активное возрождение и новое становление информационного базиса российской «мягкой силы», что вписывается в реализацию первой задачи общественной дипломатии, предлагаемой А. Долинским. В частности, в последние годы интенсифицировалась деятельность таких инструментов внешней российской информационной коммуникации, как «Russia Today», фонд «Русский мир» [3]. Однако вторая и третья задачи по реализации российской «мягкой силы», предложенные экспертом РСМД А. Долинским, на сегодняшний день не выполняются. Во многих странах мира, особенно западных, в средствах массовой информации транслируется абсолютно противоположная точка зрения относительно реализации российской внешней политики и действий РФ на международной арене. Ввиду продолжающихся в данный период времени информационных войн, искажений информации, умалчивания одних фактов, акцентирования некоторыми зарубежными партнерами внимания на негативном контексте основных новостей, связанных с внешнеполитическими акциями Москвы, довольно трудно получить объективную отклик и взвешенную оценку от зарубежной общественности.

Весьма спорно можно оценить и третью задачу, предложенную А. Долинским. Очевидно, что в условиях конфронтационного проти- 
востояния руководство того или иного государства больше опирается на отстаивание своих внешнеполитических и внешнеэкономических интересов. Учет мнения зарубежной общественности более приемлем, когда государства не вовлечены в противостояние, а поддерживают стабильный конструктивный диалог при учете интересов друг друга в условиях более позитивного международного климата.

Несомненно, «мягкая сила» России направлена на достижение долгосрочных внешнеполитических целей, о чем в феврале 2012 г. в статье «Россия и меняющийся мир» говорил президент Российской Федерации В.В. Путин. По мнению российского лидера, «soft power» - это комплекс инструментов и методов достижения внешнеполитических целей без применения оружия, а за счет информационных и других рычагов воздействия [11].

Таким образом, «мягкая сила» нацелена на обеспечение мирного диалога между различными государствами и направлена прежде всего на соблюдение интересов всех акторов современных международных отношений, в том числе и государств, которые ее проводят. Ее основная функция - созидательная, она выполняет работу по созданию благоприятных условий для расширения контактов с общественностью зарубежных стран, а также регулирует процесс формирования привлекательного государственного имиджа через трансляцию своих идей и ценностей, культуры и национального языка. В контексте исследования российской «мягкой силы» и общественной дипломатии информационными и другими рычагами воздействия можно считать непосредственно продвижение отечественной культуры и ценностей, что напрямую связано с акциями и деятельностью современной российской общественной дипломатии. В качестве примера можно привести международный конкурс «Посол русской кухни», проект «Год русского кино» и иные мероприятия по укреплению позиций русского языка, реализуемые Федеральным агентством по делам Содружества Независимых Государств, соотечественников, проживающих за рубежом и по международному гуманитарному сотрудничеству (Россотрудничество) [12].
На современном этапе исследований общественной дипломатии многие ученые соотносят ее с публичной дипломатией и при этом не всегда стремятся выявить их отличительные особенности. По мнению Б.Х. Бахриева, публичная дипломатия базируется на субъектах, включающих правительства, органы государственной власти, частные группы интересов, средства массовой информации, журналистов, а также участников различных форм и проявлений межкультурной коммуникации [1, с. 134]. Вместе с тем исследователь предпринял попытку соотнести публичную дипломатию с «мягкой силой», однако им не было представлено никаких связующих конструктов между данными понятиями.

В этой связи необходимо четко разграничить понятия «мягкой силы», публичной и общественной дипломатии для проведения дальнейшего анализа взаимосвязи последней с «мягкой силой». Публичная дипломатия в российской трактовке представляет собой тип западноевропейского общественного и межнационального сотрудничества с усиленным использованием всех возможных ресурсов средств массовой информации с целью прямого «насаждения» определенного образа жизни, в том числе демократии и других ценностей, что зачастую совпадает с реальным западным пониманием пропаганды. В свою очередь, общественная дипломатия в ее российском варианте представляет собой тесное сотрудничество всех сил гражданского общества для установления внутрироссийского диалога, а также тесных связей и взаимопонимания с представителями правительств зарубежных государств и зарубежной общественности.

Общественная дипломатия включает в себя подготовку различных материалов и документов информационного характера, книг и аудиоматериалов, а также видеоматериалов, презентующих всю необходимую информацию о государстве. При этом основной целевой аудиторией при осуществлении общественной дипломатии являются не сколько правительства зарубежных стран, сколько широкие общественные круги и иноязычные массмедиа, особая роль отводится молодежи. Рассматривая средства массовой информации зарубежных государств, важно отметить, что наи- 
более ярко общественная дипломатия проявляется в процессе проведения различных международных спортивных мероприятий, таких как чемпионат мира по футболу - 2018 в России (далее - ЧМ в России). Необходимо подчеркнуть, что идеологической программой организации ЧМ в России стала программа «Стратегическое видение», направленная на выполнение четырех массовых задач: раскрытие позитивного образа России, развитие регионов и создание устойчивого наследия, проведение праздника для футбольного сообщества «от всей души» и популяризация здорового образа жизни [8, с. 149].

По мнению исследователя Р.С. Мухаметова, к основным целям общественной дипломатии можно отнести: усиление целенаправленного влияния на зарубежную аудиторию и укрепление взаимопонимания между различными народами; формирование у зарубежной аудитории положительных взглядов на процесс проведения государством внутренней и внешней политики, а также результаты данной политики; создание благоприятных условий и обеспечение поддержки общественного мнения иностранных государств конкретными акциями России на международной арене [9, с. 85]. Кроме того, к целям российской общественной дипломатии относят достижение лучшего понимания ценностей данного государства и расширение диалога российской общественности с зарубежными партнерами [9, с. 86].

Другой отечественный исследователь И.Л. Шершнев полагает, что современная российская общественная дипломатия становится важнейшей составляющей при решении региональных, национальных и международных проблем. Она является своеобразным отражением совместной деятельности государства и института гражданского общества на международной арене в тесном взаимодействии с зарубежными партнерами [13, с. 184]. По мнению автора, общественную дипломатию России следует рассматривать как одно из измерений «мягкой силы» [13, с. 186]. При этом общественная дипломатия, являющаяся одним из неотъемлемых инструментов в осуществлении российской внешнеполитической деятельности, усиливает конкурентоспособность и многовекторность политики Рос- сийской Федерации в современном мире глобализации.

В рамках многовекторного подхода к реализации российской внешнеполитической деятельности, связанной с общественной дипломатией, некоторые исследователи обращают особое внимание на интеграционные и региональные аспекты продвижения данного общественно-политического тренда. В частности, по мнению К.П. Боришполец, страны-участники Евразийского экономического союза (далее - ЕАЭС) признают позитивную значимость общественной дипломатии как главного элемента международного воздействия, при этом у разных участников этого объединения складывается разное восприятие данного феномена [2, с. 29].

В своей работе исследователь существенно расширил перечень российских неправительственных организаций, которые осуществляют деятельность в международной сфере в рамках публичной дипломатии. К ним относятся: Совет по внешней и оборонной политике, Центр политических исследований России (ПИР-Центр), Институт стратегических оценок и анализа, Центр политических и международных исследований, Международный фонд социально-экономических и политологических исследований (Горбачев-Фонд), Институт общественного проектирования, Центр анализа стратегий и технологий, Институт современного развития, Центр мировой политики и общественной дипломатии [2, c. 26]. Автор полагает, что данные организации обеспечивают связь российского и зарубежного экспертного сообщества. Это позволяет всесторонне рассматривать крупные международные проблемы с точки зрения их глобальных последствий для всей системы международных отношений [2, с. 26-27]. К.П. Боришполец приходит к выводу, что перспективы развития общественной дипломатии зависят от двух основополагающих факторов - от расширения предметного диалога по конкретным вопросам евразийской интеграции и от создания системы многосторонних евразийских интеграционных площадок с участием государственных и негосударственных акторов не только Евразийского экономического союза, но и государств регионального окружения [2, с. 29]. 
По мнению А.Н. Марчукова, современная российская публичная дипломатия нацелена на развитие интеграционных связей и дальнейшего сотрудничества со странами зоны свободной торговли СНГ. Исследователь приходит к выводу, что в течение последних двадцати лет роль русского языка в отношениях между Россией и сопредельными государствами резким образом сократилась и поэтому Российской Федерации сегодня необходимо задуматься о наращивании своего гуманитарного присутствия за рубежом [6, c. 109]. Стоит отменить, что Россотрудничество проводит широкомасштабную работу в данном направлении. На сегодняшний день запущено множество проектов: Eurasian Week, Международный деловой форум на пространстве ЕАЭС, а также проводятся мероприятия по популяризации русского языка: День русского языка, День славянской письменности и культуры, Международный конкурс «Магистры русского языка» [12].

Рассматривая варианты развития «публичной дипломатии 2.0», А.Н. Марчуков приходит к заключению, что главным препятствием для дальнейшего развития данного феномена является отсутствие общепризнанных критериев для оценки развития деятельности публичной дипломатии [7, с. 110]. В качестве них обычно рассматривается количество подписчиков интернет-страниц, а также отдельные показатели осуществления взаимодействия с аудиторией $[7$, с. 110]. Таким образом, можно констатировать, что Россия стремится к реализации задач своей «мягкой силы» через проведение различных внешнеполитических акций и мероприятий, формой которых является непосредственно общественная дипломатия.

И.Л. Шершнев, опираясь на проведенный им контент-анализ официальных документов, материалов и источников, пришел к выводу, что нынешняя российская общественная дипломатия имеет тринадцать главных направлений деятельности: 1) повышение статуса РФ на международной арене; 2) активизация российского гражданского общества во внешнеполитической деятельности страны; 3) комплексная модернизация России, включая и ее внешнеполитическую деятельность; 4) развитие современной российской общественной дипломатии в ее гуманитарном измерении;
5) интенсификация работы с соотечественниками, находящимися за рубежом; 6) участие в общем развитии системы международных отношений; 7) улучшение имиджа Российской Федерации за рубежом; 8) ресурсное обеспечение деятельности общественной дипломатии; 9) участие России в международных интеграционных проектах; 10) интенсификация взаимодействия с религиозными организациями по поддерживанию межрелигиозного мира и религиозной толерантности; 11) противодействие фальсификации истории; 12) обеспечение прав и свобод человек; 13) активное участие в решении проблем мировой глобализации [13, с. 186-194].

Российское руководство проводит работу в рамках всех направлений, однако некоторые аспекты вышеуказанных направлений реализуются более интенсивно. Следует выделить интенсификацию работы с соотечественниками: работает Правительственная комиссия по делам соотечественников за рубежом, действует Государственная программа по оказанию содействия добровольному переселению в РФ соотечественников, проживающих за рубежом, реализуется проект «Всемирные игры юных соотечественников» [12]. Возвращаясь к рассмотрению направлений деятельности российской общественной дипломатии И.Л. Шершнева, стоит отметить, что участие России в международных интеграционных проектах осуществляется в ограниченном формате. Тем не менее в условиях изоляции РФ от крупнейших международных организаций Москва продолжает участвовать во многих интеграционных объединениях, а также остается важным звеном в развитии экономической интеграции. Что касается такого направления, как улучшение имиджа РФ за рубежом, на данный момент сложно говорить о существенных сдвигах в трансформации имиджа РФ в глазах некоторых партнеров Москвы. Поддерживать позитивный имидж Российской Федерации возможно за счет продвижение ресурсов общественной дипломатии.

Важно отметить, что общественная дипломатия проявляется и на региональном уровне, в частности в г. Волгограде и Волгоградской области. Особую роль в общественной дипломатии города играют контакты по ли- 
нии побратимского движения, важным атрибутом которого является сохранение исторической памяти о всех событиях Второй мировой войны. Как известно, г. Волгоград (Сталинград) в советское время возродил идею побратимского движения, заключающуюся в расширении сотрудничества городов-партнеров из разных стран. Волгоградские исследователи Е.Ф. Парубочая и А.А. Киселев считают побратимское движение важной формой реализации российской общественной дипломатии. На сегодняшний день оно наиболее активно проявляется во взаимоотношениях между Волгоградом и японским городом Хиросимой, пережившим тотальное разрушение во время Второй мировой войны [10].

Исходя из этого, можно сделать вывод о том, что российская общественная дипломатия выполняет множество задач, однако некоторые из них на сегодняшний день находятся на зачаточном этапе своего развития. В частности, к достаточно молодым направлениям деятельности общественной дипломатии можно отнести активное участие российского гражданского общества во внешнеполитической деятельности.

В свою очередь, противодействие фальсификации истории на протяжении длительного времени является одним из наиболее выделяющихся направлений деятельности российской общественной дипломатии. Наиболее активно стремление к гуманитарному взаимодействию с зарубежными государствами и к борьбе против фальсификации истории было отмечено в рамках выступлений делегатов 39-го заседания Российского организационного комитета «Победа», прошедшего в апреле 2017 г. в г. Москве [4]. В ходе данного мероприятия президент Российской Федерации В.В. Путин отметил важность отстаивания объективного отношения к истории, проведения последовательной и постоянной работы в части патриотического воспитания, поддерживание общественных инициатив, в частности поисковых движений и исторических реконструкций [4]. Также в своем выступлении российский президент подчеркнул важность развития связей с соотечественниками за рубежом и контактов городов-побратимов [4].

Важно подчеркнуть, что на сегодняшний день в современной России существует мас- са различных точек зрений на перспективы развития общественной дипломатии и ее взаимосвязи с российской «мягкой силой». Часть исследователей стремится отождествить «мягкую силу» и пропаганду. Кроме того, существует тенденция к соотношению публичной дипломатии и общественной дипломатии, что является не совсем верным с позиции практической реализации данных социальных феноменов.

Результаты. Таким образом, в результате проведенного исследования удалось выявить, что существуют характерные черты, объединяющие российскую общественную дипломатию и российскую «мягкую силу». Прежде всего, это стремление к созданию положительного, привлекательного имиджа Российской Федерации среди ее жителей и на международной арене, стремление к равноправному сотрудничеству со всеми зарубежными партнерами, нацеленность российской общественности на проведение диалога по дискуссионным вопросам отечественной истории и международной повестки дня, а также общая направленность на совершенствование социально-гуманитарной сферы сотрудничества. Исходя из этого, можно определить, что российская общественная дипломатия является прямым инструментом реализации «мягкой силы» современной России по следующим критериям: 1) общественная дипломатия действует через мероприятия всероссийского и международного уровней, что является непосредственной формой реализации «мягкой силы»; 2) в рамках проводимых международных мероприятий происходит процесс ретрансляции культурных, языковых, идеологических ценностей России, что может оказать влияние на зарубежную общественность в складывании представлений о России и изменении традиционно устоявшихся стереотипов; 3) этика российского общественного дипломата предусматривает признание принципов равенства, уважения и равноправного диалога, во время которого происходит продвижение ценностей российского государства и общества. Данные критерии показывают направленность общественной дипломатии России на решение актуальных практических задач российской внешней политики в краткосрочной и долгосрочной перспективах. 
Однако необходимо учитывать, что на сегодняшний день отечественная общественная дипломатия как инструмент проявления «мягкой силы» России находится в состоянии своего зарождения и становления. В настоящий момент лишь некоторые из заявленных направлений деятельности в рамках общественной дипломатии динамично развиваются. В целом общественная дипломатия как инструмент реализации российской «мягкой силы» имеет сегодня все институциональные основания для дальнейшего развития в целях реализации задач, предусмотренных современной внешнеполитической повесткой Российской Федерации.

\section{СПИСОК ЛИТЕРАТУРЫ}

1. Бахриев, Б. Х. Публичная дипломатия в современном исследовательском дискурсе / Б. Х. Бахриев // Вестник ТГУПБП. Серия общественных наук. - 2017. - № 1 (70). - С. 131-147.

2. Боришполец, К. П. Публичная дипломатия: прагматичный взгляд на разнообразие реального опыта / К. П. Боришполец // Международная аналитика. - 2018. - № 1 (23). - С. 22-32.

3. Долинский, А. Что такое общественная дипломатия и зачем она нужна России? / А. Долинский // Российский совет по международным делам. - 2012. - Электрон. текстовые дан. - Режим доступа: http://russiancouncil.ru/analytics-andcomments/analytics/chto-takoe-obshchestvennayadiplomatiya-i-zachem-ona-nuzhna-/ (дата обращения: 05.09.2018). - Загл. с экрана.

4. Заседание Оргкомитета «Победа». - Электрон. текстовые дан. - Режим доступа: http:// kremlin.ru/events/president/news/54347 (дата обращения: 11.09.2018). - Загл. с экрана.

5. Лебедева, М. М. «Мягкая сила»: понятие и подходы / М. М. Лебедева // Вестник МГИМО-Университета. - 2017. - № 3. - С. 213-222.

6. Марчуков, А. Н. «Публичная дипломатия $2.0 »$ во внешней политике Российской Федерации: проблемы и перспективы развития / А. Н. Марчуков // Вестник Московского государственного университета. Серия 25 , Международные отношения и мировая политика. - 2014. - № 3. - С. 95-114.

7. Марчуков, А. Н. «Публичная дипломатия 2.0» как инструмент внешнеполитической деятельности / А. Н. Марчуков // Вестник Волгоградского государственного университета. Серия 4 , История. Регионоведение. Международные отношения. 2014. - № 4. - C. 103-113. - DOI: http://dx.doi.org/10. 15688/jvolsu4.2014.4.10.
8. Милованова, М. В. Репрезентация образа России в медиадискурсе Германии в контексте Чемпионата мира по футболу 2018 / М. В. Милованова, М. Ю. Свинкина // Вестник Волгоградского государственного университета. Серия 2, Языкознание. - 2018. - Т. 17, № 3. -C. 148-157. - DOI: https:// doi.org/10.15688/jvolsu2.2018.3.15.

9. Мухаметов, Р. С. Специфика общественной дипломатии как инструмента внешней политики государства / Р. С. Мухаметов // Известия Уральского федерального университета. Серия 3, Общественные науки. - 2014. - № 2 (128). - С. 84-90.

10. Парубочая, Е. Ф. Волгоград и Хиросима: общественная дипломатия городов-побратимов в борьбе за мир / Е. Ф. Парубочая, А. А. Киселев. Электрон. текстовые дан. - Режим доступа: http:// www.welcomevolgogradcity.com/News.aspx?idn=496 (дата обращения: 09.09.2018). - Загл. с экрана.

11. Путин, В. В. Россия и меняющийся мир / В. В. Пугин // Российская газета. - 2012. - 27 февр. Электрон. текстовые дан. - Режим доступа: https:// rg.ru/2012/02/27/putin-politika.html (дата обращения: 07.09.2018). - Загл. с экрана.

12. Укрепление позиций русского языка // Россотрудничество. - Электрон. текстовые дан. - Режим доступа: http://rs.gov.ru/ru/activities/9 (дата обращения: 10.09.2018). - Загл. с экрана.

13. Шершнев, И. Л. Направления деятельности общественной дипломатии во внешней политике России в эпоху глобализации / И. Л. Шершнев // Вестник МГЛУ.-2015. - Вып. 2 (713). - С. 184-195.

14. Nai, J. Soft Power: The Mean to Success in World Politics. Public Affairs. - Electronic text data. Mode of access: https://www.foreignaffairs.com/ reviews/capsule-review/2004-05-01/soft-powermeans-success-world-politics (date of access: 10.09.2018). - Title from screen.

15. Public Diplomacy and Foreign Policy. Electronic text data. - Mode of access: http://politics. oxfordre.com/view/10.1093/acrefore/9780190228637. 001.0001/acrefore-9780190228637-e-471 (date of access: 09.09.2018). - Title from screen.

\section{REFERENCES}

1. Bakhriev B.Kh. Publichnaya diplomatiya $v$ sovremennom issledovatelskom diskurse [Public Diplomacy in the Modern Research Discourse]. Vestnik TGUPBP. Seriya obshchestvennykh nauk, 2017, no. 1 (70), pp. 131-147.

2. Borishpolets K.P. Publichnaya diplomatiya: pragmatichnyy vzglyad na raznoobrazie realnogo opyta [Public Diplomacy: Pragmatic View on Real Experience Variety]. Mezhdunarodnaya analitika, 2018, no. 1 (23), pp. 22-32. 
3. Dolinskiy A. Chto takoe obshchestvennaya diplomatiya i zachem ona nuzhna Rossii? [What is Public Diplomacy and Why Russia Needs It?]. Rossiyskiy sovet po mezhdunarodnym delam [Russian International Affairs Council], 2012. URL: http:// russiancouncil.ru/analytics-and-comments/analytics/ chto-takoe-obshchestvennaya-diplomatiya-i-zachemona-nuzhna-/ (accessed 5 September 2018).

4. Zasedanie Orgkomiteta «Pobeda» [Meeting of Organization Committee Pobeda]. URL: http:// kremlin.ru/events/president/news/54347 (accessed 11 September 2018).

5. Lebedeva M.M. «Myagkaya sila»: ponyatie i podkhody [Soft Power: Definition and Approaches]. Vestnik MGIMO-Universiteta, 2017, no. 3, pp. 213-222.

6. MarchukovA.N. «Publichnaya diplomatiya 2.0» vo vneshney politike Rossiyskoy Federatsii: problemy i perspektivy razvitiya [Public Diplomacy 2.0 in Foreign Policy of the Russian Federation: Problems and Perspectives of Development]. Vestnik Moskovskogo gosudarstvennogo universiteta. Seriya 25, Mezhdunarodnye otnosheniya i mirovaya politika, 2014, no. 3, pp. 95-114.

7. MarchukovA.N. «Publichnaya diplomatiya 2.0» kak instrument vneshnepoliticheskoy deyatelnosti [Public Diplomacy 2.0 as a Tool of Foreign Policy Activity]. Vestnik Volgogradskogo gosudarstvennogo universiteta. Seriya 4, Istoriya. Regionovedenie. Mezhdunarodnye otnosheniya [Science Journal of Volgograd State University. History. Area Studies. International Relations], 2014, no. 4, pp. 103-113.-DOI: http://dx.doi.org/10.15688/jvolsu4.2014.4.10.

8. Milovanova M.V., Svinkina M.Yu. Representation of Russia's Image in German Media Discourse in the Context of the 2018 FIFA World Cup. Vestnik Volgogradskogo gosudarstvennogo universiteta. Seriya 2, Yazykoznanie [Science Journal of Volgograd State University. Linguistics], 2018, vol. 17, no. 3, pp. 148-157. DOI: https://doi.org/ 10.15688/jvolsu2.2018.3.15.

9. Mukhametov R.S. Spetsifika obshchestvennoy diplomatii kak instrumenta vneshney politiki gosudarstva [Specifics of Public Diplomacy as a Tool of State Foreign Policy]. Izvestiya Uralskogo federalnogo universiteta. Seriya 3, Obshchestvennye nauki, 2014, no. 2 (128), pp. 84-90.

10. Parubochaya E.F., Kiselev A.A. Volgograd $i$ Khirosima: obshchestvennaya diplomatiya gorodovpobratimov v borbe za mir [Volgograd and Hiroshima: Public Diplomacy of Twin-Cities in the Struggle for Peace]. URL: http://www.welcomevolgogradcity.com/ News.aspx?idn=496 (accessed 9 September 2018).

11. Putin V.V. Rossiya i menyayushchiysya mir [Russia and the Changing World]. Rossiyskaya gazeta, 2012, February 27. URL: https://rg.ru/2012/02/27/putinpolitika.html (accessed 7 September 2018).

12. Ukreplenie pozitsiy russkogo yazyka [Strengthening of the Russian Language Position]. Rossotrudnichestvo [Russian Cooperation]. URL: http://rs.gov.ru/ru/activities/9 (accessed 10 September 2018).

13. Shershnev I.L. Napravleniya deyatelnosti obshchestvennoy diplomatii vo vneshney politike Rossii v epokhu globalizatsii [Activity Directions of Public Diplomacy in Russian Foreign Policy in Globalization Epoch]. Vestnik MGLU, 2015, iss. 2 (713), pp. 184-195.

14. Nai J. Soft Power: The Mean to Success in World Politics. Public Affairs. URL.: https:// www.foreignaffairs.com/reviews/capsule-review/200405-01/soft-power-means-success-world-politics (accessed 10 September 2018).

15. Public Diplomacy and Foreign Policy. URL: http://politics.oxfordre.com/view/10.1093/acrefore/ 9780190228637.001.0001/acrefore-9780190228637-e-471 (accessed 9 September 2018).

\section{Information about the Authors}

Elena F. Parubochaya, Candidate of Sciences (History), Associate Professor of Department of International Relations, Political Science and Area Studies, Volgograd State University, Prosp. Universitetsky, 100, 400062 Volgograd, Russian Federation, parubochaya@volsu.ru, https://orcid.org/0000-0002-2115-6595

Nikita V. Piskunov, Assistant, Department of International Relations, Political Science and Area Studies, Volgograd State University, Prosp. Universitetsky, 100, 400062 Volgograd, Russian Federation, piskunov@volsu.ru, https://orcid.org/0000-0002-2727-7558

\section{Информация об авторах}

Елена Федоровна Парубочая, кандидат исторических наук, доцент кафедры международных отношений, политологии и регионоведения, Волгоградский государственный университет, 
E.Ф. Парубочая, Н.В. Пискунов. Общественная дипломатия как инструмент реализации российской «мягкой силы»

просп. Университетский, 100, 400062 г. Волгоград, Российская Федерация, parubochaya@volsu.ru, https://orcid.org/0000-0002-2115-6595

Никита Владимирович Пискунов, ассистент кафедры международных отношений, политологии и регионоведения, Волгоградский государственный университет, просп. Университетский, 100, 400062 г. Волгоград, Российская Федерация, piskunov@volsu.ru, https://orcid.org/0000$0002-2727-7558$ 